\title{
Bentuk-bentuk Akronim yang Digunakan di Unit Pelaksana Teknis Dinas (UPTD) Balai Peralatan dan Perbekalan Dinas Pekerjaan Umum Provinsi Sulawesi Utara
}

\author{
Pamela Clara Loindong \\ pamelaloindong@gmail.com \\ Gayda Bachmid \\ Djeinnie Imbang \\ Pascasarjana \\ Universitas Sam Ratulangi
}

\begin{abstract}
Language is a means of human communication through social interaction with others. According to Chomsky, language is a collection of sentences, each with a certain length and built by a set of specific elements. Language is a regular system from various forms of sounds used in expressing thoughts and feelings of the users of the language. Indonesian language was born on October 28, 1928, grew and developed from the Malay language since ancient times, and has been used as a lingua franca not only in the archipelago, but also in almost all of Southeast Asia. This study examines the language based on the internal object of linguistic study; micro linguistic and one of its sub-discipline is morphology, focused on forms of acronyms used in UPTD Balai Peralatan dan Perbekalan Dinas Pekerjaan Umum Provinsi Sulawesi Utara. The research focus is on the forms of acronyms used in UPTD Balai Peralatan dan Perbekalan Dinas Pekerjaan Umum Provinsi Sulawesi Utara. There are three forms of acronyms used by the Aparatur Sipil Negera (Civil Servant) and Tenaga Harian Lepas (Intern) on UPTD Balai Peralatan dan Perbekalan Dinas Pekerjaan Umum Provinsi Sulawesi Utara, which is acronym whose form is determined by the formation process based on the theory of O'Grady, Dobrovolsky, theory of Kridalaksana. H., and one of the form does not follow the two existing theories. Of the thirty two acronyms found, twenty nine are formal acronyms in Indonesian language and the other three are informal acronyms.
\end{abstract}




\section{Pendahuluan}

Bahasa merupakan salah satu sarana komunikasi manusia melalui interaksi sosial dengan sesamanya. Bahasa dapat berfungsi jika saling memahami atau mengerti. Bahasa sangatlah penting dan dibutuhkan dalam kehidupan umat manusia. Apabila bahasa itu tidak ada, maka seseorang tidak dapat menyampaikan maksud dan tujuannya, sehingga akhirnya akan muncul kebisuan yang tidak menghasilkan apa-apa. Dalam Kamus Besar Bahasa Indonesia (Hasil Pencarian - KBBI Daring, 20I6) dinyatakan bahwa bahasa adalah sistem lambang bunyi yang arbitrer, yang digunakan oleh anggota suatu masyarakat untuk bekerja sama, berinteraksi, dan mengidentifikasikan diri-kalangan bahasa (kata-kata) yang lazim dipakai dalam lingkungan pekerjaan dan lain sebagainya. Sedangkan, menurut Chomsky (2002, hal. I3) bahasa adalah kumpulan kalimat, masing-masing dengan panjang tertentu dan dibangun oleh kumpulan elemen tertentu. Dengan demikian, dapat disimpulkan bahwa pengertian bahasa ialah sebuah sistem yang teratur dan berupa berbagai lambang bunyi yang dipakai dalam mengekspresikan pikiran serta perasaan dari pemakai bahasa tersebut.

Bahasa Indonesia adalah bahasa nasional yang digunakan di negara Republik Indonesia. Bahasa Indonesia lahir pada tanggal 28 Oktober 1928. Keputusan Kongres Bahasa Indonesia II tahun 1954 di Medan, antara lain, dinyatakan bahwa bahasa Indonesia berasal dari bahasa Melayu. Bahasa Indonesia tumbuh dan berkembang dari bahasa Melayu yang sejak zaman dulu sudah dipergunakan sebagai bahasa perhubungan (lingua franca) bukan hanya di Kepulauan Nusantara, melainkan juga hampir di seluruh Asia Tenggara (Marsono, 20II).

Kajian ilmiah terhadap bahasa disebut linguistik. Secara umum linguistik dapat dikatakan merupakan ilmu yang mempelajari bahasa sebagai objeknya. Linguistik adalah ilmu yang merupakan penyelidikan bahasa secara ilmiah. Definisi itu mungkin dapat diperjelas sedikit dengan menguraikan secara lebih terperinci pengertian-pengertian yang terkandung dalam batasan "ilmiah". Untuk sementara, cukuplah dikatakan bahwa maksud pengkajian atau studi bahasa secara ilmiah adalah penyelidikan bahasa melalui pengamatan-pengamatan yang teratur dan yang secara empiris dapat dibuktikan benar atau tidaknya serta mengacu kepada suatu teori umum tentang struktur bahasa. (Lyons, J., I995:I). Sub disiplin linguistik dapat dikelompokkan berdasarkan: objek kajiannya adalah bahasa pada umumnya atau bahasa tertentu, objek kajiannya adalah bahasa pada masa tertentu atau bahasa sepanjang masa, objek kajiannya adalah struktur internal bahasa itu atau bahasa itu dalam kaitannya dengan berbagai faktor di luar bahasa, tujuan 
pengkajiannya apakah untuk keperluan teori atau untuk terapan, dan teori atau aliran yang digunakan untuk menganalisis objeknya. Berdasarkan objek kajiannya, apakah bahasa pada umumnya atau bahasa tertentu linguistik dapat dibedakan menjadi linguistik mikro (mikrolinguistik) dan linguistik makro (makrolinguistik). Linguistik mikro mengarahkan kajiannya pada struktur internal bahasa. Dalam linguistik mikro ada beberapa sub disiplin yaitu; fonologi yang menyelidiki tentang bunyi bahasa, morfologi yang menyelidiki tentang morfem atau kata dan proses-proses pembentukannya, sintaksis yang menyelidiki tentang satuan-satuan kata, semantik yang menyelidiki makna bahasa dan leksikologi yang menyelidiki leksikon atau kosakata. (Online Linguistic Dictionary)

Pada penelitian kali ini penulis meneliti bahasa berdasarkan objek kajiannya yaitu linguistik mikro yang salah satu sub disiplinnya adalah morfologi dan berfokus pada bentuk- bentuk akronim yang digunakan di UPTD Balai Peralatan dan Perbekalan Dinas Pekerjaan Umum Provinsi Sulawesi Utara.

Morphology is a part of linguistic competence involves the ability to construct and interpret words. The system of categories and rules involved in word formation is called morphology. Morphological analysis focusses on the lexicon, or dictionary, component of the grammar. The lexicon consists of two parts. The first is a list of all the items in the vocabulary of the language. The lexical entry for each item includes information about its pronunciation, its meaning, its syntactic category and subcategorization frame, and various related facts. (O’Grady, Dobrovolsky, I987:I27). Morfologi adalah bagian dari kompetensi linguistik melibatkan kemampuan untuk menyusun dan menafsirkan kata-kata. Sistem kategori dan aturan yang terlibat dalam penyusunan kata disebut morfologi. Analisis morfologi berfokus pada leksikon, atau kamus, komponen tata bahasa. Leksikon terdiri dari dua bagian. Yang pertama adalah daftar semua item kosakata dalam bahasa. Entri leksikal untuk setiap item termasuk informasi tentang pengucapan, arti, kategori sintaksis dan bagan subkategorisasi, dan berbagai fakta terkait. (O'Grady, Dobrovolsky, I987:I27). Dengan kata lain Morfologi adalah cabang linguistik yang mengidentifikasi satuan-satuan dasar bahasa sebagai satuan gramatikal. Morfologi mempelajari seluk-beluk pembentukan kata serta pengaruh perubahan-perubahan bentuk kata terhadap golongan dan arti kata. Ada beberapa pembentukan kata baru (word formation) secara bebas misalnya blending, clipping, acronim dan lain sebagainya (Plag I., 2002). Sekali lagi, penelitian ini berfokus kepada akronim.

Acronyms are formed from the initial sounds or letters of a string of words, such as the name of an organization or a scientific expression. Some examples of acronyms include 
UNICEF for United Nations International Children's Emergency Fund, CIDA for Canadian International Development Agency, ACOL for Alberta Conference on Language, and CUSO for Canadian University Students Overseas. Where the combined initial letters follow the pronunciation patterns of English, the string can be pronounced as a word, such as NATO (North Atlantic Treaty Organization). (O’Grady, Dobrovolsky, I987:I4I). Akronim terbentuk dari suara awal atau huruf dari untaian kata-kata, seperti nama sebuah organisasi atau ekspresi ilmiah. Beberapa contoh akronim termasuk UNICEF (United Nations International Children's Emergency Fund), CIDA (Canadian International Development Agency), ACOL (Alberta Conference on Language), dan CUSO (Canadian University Students Overseas). Apabila huruf awal yang dikombinasikan mengikuti pola pengucapan bahasa Inggris (atau bahasa yang lain, dalam hal ini bahasa Indonesia), akronim ini dapat diucapkan sebagai kata, contohnya NATO (North Atlantic Treaty Organization). (O’Grady, Dobrovolsky, I987:I4I).

Akronim adalah kependekan yang berupa gabungan huruf atau suku kata atau bagian lain yang ditulis dan dilafalkan sebagai kata yang sesuai dengan kaidah fonotaktik bahasa bersangkutan. (Kridalaksana, H., 2009:5)

Penulis memilih untuk memfokuskan penelitian ini pada bentuk-bentuk akronim yang digunakan di UPTD Balai Peralatan dan Perbekalan Dinas Pekerjaan Umum Provinsi Sulawesi Utara, dikarenakan, pertama pengalaman empiris yang penulis alami yaitu saat mengunjungi UPTD Balai Peralatan dan Perbekalan Dinas Pekerjaan Umum Provinsi Sulawesi, penulis secara tidak sengaja mendengar beberapa istilah yang tidak lazim didengarkan, yang setelah penulis tanyakan mengenai istilah tersebut kepada sumbernya, ternyata yang penulis kira merupakan istilah tertentu tersebut merupakan akronim sehingga penulis ingin mengetahui lebih dalam mengenai bentuk-bentuk akronim apa saja yang digunakan Aparatur Sipil Negara (ASN) dan Tenaga Harian Lepas (THL) pada UPTD Balai Peralatan dan Perbekalan Dinas Pekerjaan Umum Provinsi Sulawesi Utara dalam berinteraksi dan menjalankan tugas mereka sehari-hari sehingga menimbulkan efek praktis dalam komunikasi mereka. Karena dengan menggunakan akronim, mereka tidak harus mengucapkan sederet kata-kata yang begitu panjang, tetapi cukup dengan menggunakan akronim saja maksud mereka sudah dapat tersampaikan dengan baik. Kedua, setelah peneliti membaca beberapa penelitian terdahulu mengenai akronim, peneliti sangat tertarik dengan penelitian Noviatri dan Reniwati pada tahun 2015 yang berjudul "Singkatan dan Akronim dalam Surat Kabar: Kajian Bentuk dan Proses". Fokus penelitian mereka yaitu 
mendeskripsikan bentuk-bentuk singkatan dan akronim yang digunakan dalam surat kabar dengan menjelaskan proses pembentukannya. Mereka menggunakan teori Kridalaksana dan hasilnya ditemukan I562 bentuk singkatan dan akronim dalam surat kabar dengan 9 proses, 3 proses di antaranya merupakan proses yang baru; serta 896 bentuk akronim yang digunakan dalam surat kabar dengan 3I proses, yang mana ditemukan 9 buah proses baru.

Penulis memiliki ketertarikan untuk mengetahui bagaimana proses pembentukan akronim baru yang mungkin juga terjadi di UPTD Balai Peralatan dan Perbekalan Dinas Pekerjaan Umum Provinsi Sulawesi Utara. Kedua alasan inilah yang menjadi dasar penulis untuk melaksanakan penelitian mengenai bentuk-bentuk akronim di UPTD Balai Peralatan dan Perbekalan Dinas Pekerjaan Umum Provinsi Sulawesi Utara.

\section{Rumusan Masalah}

Berdasarkan latar belakang di atas, maka penulis merumuskan masalah sebagai berikut:

I. Apa saja bentuk-bentuk akronim yang digunakan di UPTD Balai Peralatan dan Perbekalan Dinas Pekerjaan Umum Provinsi Sulawesi Utara?

2. Bagaimana proses pembentukannya?

\section{Tujuan Penelitian}

Berdasarkan rumusan masalah, yang menjadi tujuan penelitian yaitu:

I. Mengidentifikasi bentuk-bentuk akronim yang digunakan di UPTD Balai Peralatan dan Perbekalan Dinas Pekerjaan Umum Provinsi Sulawesi Utara.

2. Mengidentifikasi dan menjelaskan proses pembentukan akronim yang digunakan di UPTD Balai Peralatan dan Perbekalan Dinas Pekerjaan Umum Provinsi Sulawesi Utara.

\section{Kerangka Teoritis}

Akronim adalah kependekan yang berupa gabungan huruf atau suku kata atau bagian lain yang ditulis dan dilafalkan sebagai kata yang sesuai dengan kaidah fonotaktik bahasa bersangkutan. (Kridalaksana, Kamus Linguistik, 2009, hal. 5)

The acronym must result in a phoneme sequence consisting of one or several syllables which correspond to the syllable structure of English. Example: CROP:

Christian Rural Overseas Program, laser: Light Amplification by Stimulated Emission of Radiation. (McCully \& Holmes, I988, p. 30)

Akronim harus menghasilkan rentetan fonem yang mengandung satu atau sejumlah suku kata, yang berhubungan dengan struktur suku kata bahasa Inggris (atau 
bahasa lainnya). Contoh: CROP: Christian Rural Overseas Program, laser: Light Amplification by Stimulated Emission of Radiation. (McCully \& Holmes, 1988, p. 30)

Acronyms are formed from the initial sounds or letters of a string of words, such as the name of an organization or a scientific expression. Some examples of acronyms include UNICEF for United Nations International Children's Emergency Fund, CIDA for Canadian International Development Agency, ACOL for Alberta Conference on Language, and CUSO for Canadian University Students Overseas. Where the combined initial letters follow the pronunciation patterns of English, the string can be pronounced as a word, such as NATO (North Atlantic Treaty Organization). (O’Grady \& Dobrovolsky, I987, p. I4I)

Akronim terbentuk dari suara awal atau huruf dari untaian kata-kata, seperti nama sebuah organisasi atau ekspresi ilmiah. Beberapa contoh akronim termasuk UNICEF (United Nations International Children's Emergency Fund), CIDA (Canadian International Development Agency), ACOL (Alberta Conference on Language), dan CUSO (Canadian University Students Overseas). Apabila huruf awal yang dikombinasikan mengikuti pola pengucapan bahasa Inggris (atau bahasa yang lain, dalam hal ini bahasa Indonesia), akronim ini dapat diucapkan sebagai kata, contohnya NATO (North Atlantic Treaty Organization). (O’Grady \& Dobrovolsky, I987, p. I4I)

As defined by Webster's dictionary, acronym is a word formed from the initial letters of the successive parts of a compound term. (ex: radar). (Definition of Acronym, 20I6)

Seperti yang ditulis dalam Kamus Webster's Dictionary, akronim adalah kata yang terbentuk dari huruf awal dari istilah komponen yang bersusulan (contoh: radar). (Definition of Acronym, 20I6)

Hartanto (I995) menjelaskan akronim adalah bentuk singkatan yang berupa gabungan huruf awal, gabungan suku kata ataupun kombinasi huruf dan suku kata dari deret kata dan yang ditulis serta dilafalkan sebagai kata yang wajar; contoh Mayjen (Mayor Jenderal).

Dalam penelitian ini penulis menggunakan kedua teori yang telah disebutkan di atas yaitu teori mengenai akronim oleh O’Grady, Dobrovolsky (1987:I4I) dan Kridalaksana. H. (2009:5).

\section{Metodologi}




\section{Tempat dan Waktu Penelitian}

Penelitian dilakukan di UPTD Balai Peralatan dan Perbekalan Dinas Pekerjaan Umum Provinsi Sulawesi Utara pada tanggal 9 dan Io November 20I6. Pada tanggal 9 November 2016 penelitian dilakukan pada pukul I5.00-I7.00 WITA dan pada tanggal IO November 2016 penelitian dilakukan pada pukul I6.00-I7.00 WITA.

\section{Informan}

Jumlah total Aparatur Sipil Negara (ASN) dan Tenaga Harian Lepas (THL) pada UPTD Balai Peralatan dan Perbekalan Dinas Pekerjaan Umum Provinsi Sulawesi Utara adalah 35 (tiga puluh lima orang). Ada empat orang informan yang penulis wawancarai, yaitu 2 orang ASN dan 2 orang THL.

\section{Metode Pengumpulan Data}

Metode pengumpulan data yang penulis lakukan adalah metode SLBC (simak bebas lihat dan cakap) dengan wawancara yang tidak terstruktur. Pertama, penulis memberi penjelasan singkat mengenai akronim, kemudian ketika informan telah memahami apa yang dimaksud dengan akronim, penulis kemudian menanyakan akronim apa saja yang biasanya mereka gunakan dalam komunikasi mereka sehari-hari dengan rekan kerja maupun atasan dan bawahan mereka dan jawaban dari mereka yang berkaitan dengan penggunaan akronim disimak dan dicatat oleh penulis dalam buku.

\section{Teknik Analisis Data}

Data yang dikumpulkan diklasifikasi berdasarkan teori O'Grady, Dobrovolsky (1987:I4I) dan Kridalaksana (2009:5) mengenai akronim. 


\section{Pembahasan}

A. Bentuk-Bentuk Akronim yang Digunakan di UPTD Balai Peralatan dan Perbekalan Dinas Pekerjaan Umum Provinsi Sulawesi Utara

Dari hasil penelitian penulis, berikut ini adalah akronim-akronim yang penulis temukan digunakan di UPTD Balai Peralatan dan Perbekalan Dinas Pekerjaan Umum Provinsi Sulawesi Utara.

I. albert: alat berat

2. bapertarum: badan perumahan tabungan rumah

3. CALK: Catatan Atas Laporan Keuangan

4. cikar: cipta karya

5. EPRA: Evaluasi Pengawasan Realisasi Anggaran

6. jakon: jasa konstruksi

7. Kabag: Kepala Bagian

8. Kaban: Kepala Badan

9. Kabid: Kepala Bidang

Io. Kadis: Kepala Dinas

II. kanwil: kantor wilayah

I2. Karip: kartu inventaris pensiun

I3. Karis: kartu istri

I4. Karo: Kepala Biro

I5. Karpeg: kartu pegawai

I6. Karsu: kartu suami

I7. Kasi: Kepala Seksi

I8. Kasubag: Kepala Sub Bagian

I9. Kasubid: Kepala Sub Bidang

20. kendis: kendaraan dinas

2I. KIB: Kartu Inventaris Barang

22. konreg: konvensi regional

23. mami: makan minum

24. monev: monitoring dan evaluasi

25. musrenbang: musyawarah perencanaan pembangunan

26. perkim: perumahan permukiman

27. perumnas: perumahan nasional 
28. renja: rencana kerja

29. renstra: rencana strategis

30. SIMDA: Sistem Informasi Keuangan Daerah

3I. SIRUP: Sistem Informasi Rencana Umum Pengadaan

32. taspen: tabungan asuransi pensiun

Total dari akronim yang digunakan di UPTD Balai Peralatan dan Perbekalan Dinas Pekerjaan Umum Provinsi Sulawesi Utara adalah 32 akronim.

B. Proses Pembentukan Akronim yang Digunakan di UPTD Balai Peralatan dan Perbekalan Dinas Pekerjaan Umum Provinsi Sulawesi Utara berdasarkan teori O'Grady, Dobrovolsky dan Kridalaksana. H.

Bentuk akronim di UPTD Balai Peralatan dan Perbekalan Dinas Pekerjaan Umum Provinsi Sulawesi Utara yang proses pembentukannya yang digunakan berdasarkan teori dari O'Grady, Dobrovolsky, (I987:I4I) yang menyatakan bahwa Acronyms are formed from the initial sounds or letters of a string of words, such as the name of an organization or a scientific expression. Some examples of acronyms include UNICEF for United Nations International Children's Emergency Fund, CIDA for Canadian International Development Agency, ACOL for Alberta Conference on Language, and CUSO for Canadian University Students Overseas. Where the combined initial letters follow the pronunciation patterns of English, the string can be pronounced as a word, such as NATO (North Atlantic Treaty Organization). (O’Grady, Dobrovolsky, I987:I4I). Akronim terbentuk dari suara awal atau huruf dari untaian kata-kata, seperti nama sebuah organisasi atau ekspresi ilmiah. Beberapa contoh akronim termasuk UNICEF (United Nations International Children's Emergency Fund), CIDA (Canadian International Development Agency), ACOL (Alberta Conference on Language), dan CUSO (Canadian University Students Overseas). Apabila huruf awal yang dikombinasikan mengikuti pola pengucapan bahasa Inggris (atau bahasa yang lain, dalam hal ini bahasa Indonesia), akronim ini dapat diucapkan sebagai kata, contohnya NATO (North Atlantic Treaty Organization). (O’Grady, Dobrovolsky, I987:I4I).

Ciri khas pada bentuk akronim ini ialah dibuat dengan mengambil awalan huruf pada kata-kata dan dirangkai menjadi satu kata.

I. CALK: Catatan Atas Laporan Keuangan

2. EPRA: Evaluasi Pengawasan Realisasi Anggaran

3. KIB: Kartu Inventaris Barang

4. SIMDA: Sistem Informasi Keuangan Daerah 
5. SIRUP: Sistem Informasi Rencana Umum Pengadaan

Lima akronim di atas telah memenuhi kriteria pembentukan akronim dari O’Grady, Dobrovolsky dan empat di antaranya merupakan akronim yang baku dalam bahasa Indonesia, kecuali akronim SIRUP: Sistem Informasi Rencana Umum Pengadaan yang bukan merupakan akronim baku dalam bahasa Indonesia.

Bentuk akronim di UPTD Balai Peralatan dan Perbekalan Dinas Pekerjaan Umum Provinsi Sulawesi Utara yang proses pembentukannya sesuai dengan teori dari Kridalaksana. H. yang menyatakan bahwa akronim adalah kependekan yang berupa gabungan huruf atau suku kata atau bagian lain yang ditulis dan dilafalkan sebagai kata yang sesuai dengan kaidah fonotaktik bahasa bersangkutan.

I. albert: alat berat

2. bapertarum: badan perumahan tabungan rumah

3. cikar: cipta karya

4. jakon: jasa konstruksi

5. Kabag: Kepala Bagian

6. Kaban: Kepala Badan

7. Kabid: Kepala Bidang

8. Kadis: Kepala Dinas

9. kanwil: kantor wilayah

IO. karip: kartu inventaris pensiun

II. karis: kartu istri

I2. Karo: Kepala Biro

I3. karpeg: kartu pegawai

I4. karsu: kartu suami

I5. Kasie: Kepala Seksi

I6. Kasubag: Kepala Sub Bagian

I7. Kasubid: Kepala Sub Bidang

I8. kendis: kendaraan dinas

I9. konreg: konvensi regional

20. mami: makan minum

2I. monev: monitoring dan evaluasi

22. musrenbang: musyawarah perencanaan pembangunan 
23. perkim: perumahan permukiman

24. perumnas: perumahan nasional

25. renja: rencana kerja

26. renstra: rencana strategis

27. taspen: tabungan asuransi pensiun

Akronim-akronim di atas berdasarkan proses pembentukannya ini telah memenuhi kaidah dari teori Kridalaksana, H., (2009: 5) dan merupakan akronim yang sudah baku digunakan dalam Bahasa Indonesia. Dengan pengecualian tiga akronim yaitu akronim Kasie (Kepala Seksi) yang ternyata tidak memenuhi teori yang dipaparkan oleh Kridalaksana dalam proses pembentukannya tetapi merupakan akronim yang sudah baku dalam bahasa Indonesia sedangkan dua akronim lainnya yaitu kendis (kendaraan dinas) dan albert (alat berat), bukan merupakan akronim baku dalam Bahasa Indonesia tetapi telah memenuhi kaidah pembentukan fonotaktik akronim sesuai dengan teori dari Kridalaksana. Kedua akronim ini hanya dikenal oleh Aparatur Sipil Negara (ASN) dan Tenaga Harian Lepas (THL) pada UPTD Balai Peralatan dan Perbekalan Dinas Pekerjaan Umum Provinsi Sulawesi Utara dan sejumlah kelompok lain yang memiliki hubungan kerja sama dengan UPTD Balai Peralatan dan Perbekalan Dinas Pekerjaan Umum Provinsi Sulawesi Utara.

Sesuai dengan pembahasan di atas, pertama, berdasarkan proses pembentukannya, ada tiga bentuk akronim yang digunakan di UPTD Balai Peralatan dan Perbekalan Dinas Pekerjaan Umum Provinsi Sulawesi Utara, yaitu akronim yang proses pembentukannya berdasarkan teori O'Grady, Dobrovolsky yang ciri utamanya adalah mengambil hurufhuruf pertama dari kata-kata yang akan dibentuk menjadi akronim, bentuk akronim yang kedua adalah akronim yang proses pembentukannya berdasarkan teori Kridalaksana. H. yang ciri utamanya mengambil suku kata awal dari kata-kata yang akan dibentuk menjadi akronim dan bentuk akronim yang ketiga belum diketahui adalah bentuk akronim apa karena tidak sesuai dengan kedua teori di atas yaitu akronim Kasie.

Kedua, ditemukan tiga akronim yang tidak baku dalam bahasa Indonesia yang digunakan di UPTD Balai Peralatan dan Perbekalan Dinas Pekerjaan Umum Provinsi Sulawesi Utara, yaitu SIRUP, albert dan kendis. Proses pembentukan untuk SIRUP dan albert tidak dapat ditemukan oleh penulis, sedangkan untuk proses pembentukan kendis, ternyata diciptakan secara spontan oleh bapak bendahara Ferdinan Labawo pada awal tahun 20I6, kemudian menjadi familiar dan berterima, sehingga sampai saat ini terus 
digunakan di UPTD Balai Peralatan dan Perbekalan Dinas Pekerjaan Umum Provinsi Sulawesi Utara. 


\section{Simpulan}

Berdasarkan penelitian yang telah dilakukan ada tiga puluh dua akronim yang digunakan di UPTD Balai Peralatan dan Perbekalan Dinas Pekerjaan Umum Provinsi Sulawesi Utara. Berdasarkan klasifikasi bentuknya, ditemukan tiga bentuk akronim yang digunakan oleh Aparatur Sipil Negara (ASN) dan Tenaga Harian Lepas (THL) pada UPTD Balai Peralatan dan Perbekalan Dinas Pekerjaan Umum Provinsi Sulawesi Utara, yaitu akronim yang bentuknya ditentukan oleh proses pembentukannya berdasarkan teori O'Grady, Dobrovolsky yang ciri utamanya adalah mengambil huruf-huruf pertama dari kata-kata yang akan dibentuk menjadi akronim, bentuk akronim yang kedua adalah akronim yang proses pembentukannya berdasarkan teori Kridalaksana. H. yang ciri utamanya mengambil suku kata awal dari kata-kata yang akan dibentuk menjadi akronim dan bentuk akronim yang ketiga belum diketahui adalah bentuk akronim apa karena tidak sesuai dengan kedua teori di atas yaitu akronim Kasie. Dari tiga puluh dua akronim yang ditemukan, dua puluh sembilan akronim yang digunakan merupakan akronim baku dalam bahasa Indonesia dan tiga lainnya yaitu SIRUP: Sistem Informasi Rencana Umum Pengadaan, albert (alat berat) dan kendis (kendaraan dinas) bukan merupakan akronim yang baku dalam bahasa Indonesia. Proses pembentukan untuk SIRUP dan albert tidak dapat ditemukan oleh penulis, sedangkan untuk proses pembentukan kendis, ternyata diciptakan secara spontan oleh bapak bendahara Ferdinan Labawo pada awal tahun 20I6, kemudian menjadi familiar dan berterima, sehingga sampai saat ini terus digunakan di UPTD Balai Peralatan dan Perbekalan Dinas Pekerjaan Umum Provinsi Sulawesi Utara. Semoga penelitian ini bermanfaat bagi pembaca dan semoga bahasa kita akan lebih diperkaya lagi dengan bentuk-bentuk akronim baru yang mungkin akan muncul di masa depan yang dapat membantu keefektifan dalam berkomunikasi kita semua. 


\section{DAFTAR PUSTAKA}

Chaer, A. (2007). Leksikologi \& Leksikografi Indonesia. Jakarta: Rineka Cipta.

Chomsky, N. (2002). Syntactic Structures. Berlin: de Gruyter.

Definition of Acronym. (2016). Diambil kembali dari Merriam-Webster: https://www.merriam-webster.com/dictionary/acronym

Dhianari, N. (20II). Ragam Bahasa Kaskus.

Dhianari, N. M. (20I5). Akronim yang Digunakan di Komunitas Jejaring Sosial Kaskus.

Giyatmi, Hastuti, E. D., Wijayava, R., \& Arumi, S. (20I4). The Analysis of English Word Formations Used on Brand Names Found in Indonesian Products. Register, I79204.

Halliday, M. A., Teubert, W., Yallop, C., \& Čermáková, A. (2004). Lexicology and Corpus Lingusitics: An Introduction. New York: Continuum.

Hartanto, J. S. (1995). Pedoman Umum Pembentukan Istilah dan Pedoman EYD. Surabaya: Indah.

Hasil Pencarian - KBBI Daring. (20I6). Diambil kembali dari KBBI Daring: http://kbbi.kemendikbud.go.id/entri/bahasa

Kridalaksana, H. (2009). Kamus Linguistik. Jakarta: Gramedia Pustaka Utama.

Lyons, J. (1995). Pengantar Teori Linguistik (Terjemahan oleh I. Soetikno). Jakarta: Sun Printing.

Marsono. (20II). Morfologi - Bahasa Indonesia dan Nusantara. Jogjakarta: Gadjah Mada University Press.

Marthawati, A. I. (20II). Penggunaan Istilah, Deiksis, Singkatan, dan Akronim dalam Situs Jejaring Sosial Facebook.

McCully, C. B., \& Holmes, M. (I988). Some Notes on the Structure of Acronyms. Lingua(74), 27-43.

O’Grady, W., \& Dobrovolsky, M. (1987). Contemporary Linguistic Analysis - An Introduction. Toronto: Copp Clark Pitman Ltd.

Plag, I. (2002). Word-formation in English. Cambridge: Cambridge University Press.

Reniwati, \& Noviatri. (20I5). Singkatan dan Akronim dalam Surat Kabar: Kajian Bentuk dan Proses. Jurnal Arbitrer, 28-43.

Suandi, I. N. (20I4). Sosiolinguistik. Yogyakarta: Graha Ilmu.

Susdamita, R. A., Faizah, H., \& Jalil, A. (2015). Akronim dalam Indonesia Lawak Klub (ILK). Jurnal Bahasa, 2I7-224.

William O'Grady, M. D. (1987). Contemporary Linguistic Analysis - An Introduction. Toronto: Copp Clark Pitman Ltd.

Zaim, M. (2015). Pergeseran Sistem Pembentukan Kata Bahasa Indonesia: Kajian Akronim, Blending, dan Kliping. Linguistik Indonesia, I73-I92. 